\title{
LAS ACTITUDES LINGÜÍSTICAS EN LA COMUNIDAD DE MAJAYURA (LA GUAJIRA): UN ESTUDIO DESDE LOS COMPONENTES COGNITIVO Y EMOCIONAL
}

\author{
Aura Rosa Salazar Caro \\ Universidad Popular del Cesar (Colombia) \\ aurarosasalazar@unicesar.edu.co \\ Juan Daniel Ospino Palmera \\ Universidad Popular del Cesar (Colombia) \\ jdanielospino@unicesar.edu.co
}

Recibido: 05/02/2021 - Aprobado: 26/03/2021 - Publicado: 30/07/2021

DOI: doi.org/10.17533/udea.lyl.n80a15

\begin{abstract}
Resumen: Este artículo analiza las actitudes lingüísticas de la comunidad wayuu de Majayura, La Guajira, hacia el wayuunaiki, a partir de elementos como la lealtad, el orgullo y la conciencia lingüísticos. Es un estudio etnográfico fundamentado en la descripción e interpretación de las creencias, sentimientos y comportamientos lingüísticos de los hablantes. Los datos revelan que la comunidad tiene un grado alto de lealtad y orgullo por su lengua, así como conciencia de la necesidad de conservarla. La realidad sociolingüística de la comunidad es una muestra de la resistencia a un escenario de contacto que privilegia el uso del español.
\end{abstract}

Palabras clave: Majayura; wayuunaiki; etnografía; actitudes lingüísticas; lenguas en contacto.

\section{LINGUISTIC ATTITUDES IN THE COMMUNITY OF MAJAYURA (LA GUAJIRA): A STUDY FROM COGNITIVE AND EMOTIONAL COMPONENTS}

\begin{abstract}
This article analyzes the linguistic attitudes of the Wayuu community of Majayura, La Guajira, towards Wayuunaiki, based on elements such as loyalty, linguistic pride and linguistic awareness. This is an ethnographic study that stems from the description and interpretation of the beliefs, feelings and linguistic behaviors of the indigenous community. The data reveals the Wayuu of Majayura have a high level of loyalty and pride in their language, and they are conscious of the need to preserve it. The sociolinguistic reality of the community is a projection of resistance in a context that privileges the use of Spanish.
\end{abstract}

Key words: Majayura; Wayuunaiki; ethnography; linguistic attitudes; linguistic contact. 


\section{Introducción}

$\mathrm{L}$

as actitudes lingüísticas constituyen aspectos centrales en la planificación lingüística y los proyectos de revitalización de las lenguas indígenas. Andrade (2016) señala que es importante conocer las actitudes

hacia las lenguas nativas dada su influencia en el uso y mantenimiento de estas. Este hecho explica por qué durante los últimos años ha aumentado el número de trabajos centrados en las actitudes de los pueblos indígenas hacia sus lenguas, y los estudiosos del lenguaje han señalado el lugar de las actitudes lingüísticas en la conservación y el mantenimiento del patrimonio lingüístico de la humanidad.

En Colombia se hablan 68 lenguas nativas. Estas lenguas se clasifican en tres tipos: las criollas de los pueblos raizal y palenquero, las indoeuropeas —romanés o shib romaní y sus variantes - y las lenguas indoamericanas o indígenas (Ministerio de Cultura, 2013). El país presenta un plurilingüismo caracterizado por la evidente desigualdad de las lenguas indígenas y criollas frente al español, catalogado por Landaburu (2004,2005) como «el vehículo dominante» (p. 4). ${ }^{1}$ Para Soler (1999), la condición del español como lengua oficial frente a las lenguas indígenas es una muestra de la posición social y política de las minorías. En el grupo de lenguas indígenas, por otra parte, se encuentra la lengua wayuunaiki, la cuales hablada por cerca de 334939 personas, que representan el $89,1 \%$ de la población wayuu (DANE, 2019a), . Tal lengua pertenece a la familia lingüística arawak, subfamilia maipureana, tronco norte (Etxebarria, 2012). Frente a la misma, Tovar (1986) señala que el sistema lingüístico de los wayuu es la lengua más activa y hablada de la familia lingüística arawak.

En este artículo se analizan las actitudes lingüísticas de los wayuu residentes en Majayura, La Guajira, hacia el wayuunaiki, a partir de los componentes cognitivo y emotivo de las actitudes. ${ }^{2}$ El objetivo es dilucidar parámetros actitudinales como la conciencia sociolingüística y los sentimientos de lealtad y orgullo de la comunidad hacia su lengua. De este modo, se busca aportar a la reflexión acerca del papel de las actitudes lingüísticas en los procesos de revitalización de las lenguas nativas. En efecto, los estudios de actitudes resultan determinantes para reavivar las lenguas indígenas y, así, proteger la diversidad étnica y cultural del país, como lo establece el artículo 7 de la Constitución Política de Colombia (Congreso de la República, 1991), porque los juicios o valoraciones de los hablantes inciden en sus comportamientos lingüísticos.

El artículo está organizado de la siguiente manera. En primer lugar, se sitúa la comunidad de Majayura en términos geográficos y lingüísticos. Después, se plantea la reflexión teórica en torno al constructo de actitudes y su medición en sociolingüística. Seguidamente se incluyen los aspectos metodológicos que orientaron el trabajo y se presentan los resultados correspondientes a cada tópico. Al final se señalan algunas conclusiones.

1. Landaburu $(2004,2005)$ usa la denominación castellano en lugar de español.

2. El modelo mentalista contempla tres componentes (cognitivo, emotivo y conativo). Sin embargo, en este artículo se analizan solamente los indicadores asociados a los dos primeros. 


\section{Situación geográfica y lingüística de los wayuu}

Los wayuu se encuentran ubicados en la península de La Guajira al norte de Colombia y al noroeste de Venezuela en el estado de Zulia, sobre el mar Caribe. Ocupan un área de 1080336 hectáreas localizadas en el resguardo de la Alta y Media Guajira, y ocho resguardos más ubicados en el sur, la Media Guajira y la reserva de Carraipía (Ministerio del Interior, 2010). Representan el 0,9 \% del total de la población nacional y el $20 \%$ del total de la población indígena del país (Ramírez, 2019). Según el último censo del DANE (2019a), existen 380 460 personas que se reconocen como wayuu en el país. Del total de la población, el 84,4\% habita en áreas rurales y el 11,6\% restante se encuentra en la cabecera municipal (DANE, 2019a).

Como se puede observar, la wayuu es la etnia indígena más numerosa de la península de La Guajira y del país (Observatorio del Programa Presidencial de Derechos Humanos y DIH, 2013, p. 2). El censo del DANE de 2018 reveló que el 89,4 \% del pueblo wayuu se concentra en cuatro municipios de La Guajira: Uribía, con el 41,7 \%; Manaure, con el 18,7 \%; Maicao, con el 17,9 \%; y Riohacha, con el 13,3 \% (DANE, 2019a). Es necesario mencionar que «los wayuu se caracterizan por ser poli-residenciales, y no nómadas, lo cual supone una adscripción territorial local rigurosa» (Observatorio del Programa Presidencial de Derechos Humanos y DIH, 2013, p. 3).Del total de la población de La Guajira, el 41,7 \% se reconoce como indígena, el 12,6 \% como negro(a), mulato(a) o afrodescendiente y el 45,4 \% no se reconoce bajo ninguno de los grupos étnicos incluidos en el censo (DANE, 2019b).

Del total de la población indígena que habita la Guajira (394.683), 94 \% es wayuu, 3,3 \% es wiwa, 1,7\% es kogui, $0,5 \%$ es arhuaco y el 0,5\% restante pertenece a pueblos no especificados (DANE, 2019a).

En la región de Majayura se hablan principalmente dos lenguas ${ }^{3}$, el español y el wayuunaiki. Los wayuu son en su mayoría bilingües, aunque una fracción de ellos es monolingüe en la Media y Alta Guajira (Ministerio del Interior, 2010). Los wayuu de la Península, por su parte, se caracterizan por ser bilingües, y en algunas comunidades se presentan situaciones de diglosia debido a que no solo coexisten las dos lenguas; sino que además los ámbitos de uso de cada una de ellas están claramente diferenciados, y dependen de la situación comunicativa. En este artículo se asume la diglosia a partir de Gimeno Menéndez (2006), quien expone que el concepto inicial de diglosia fue revisado por Fishman (1967) y ampliado a las comunidades multilingües y a todas las situaciones sociales en las que se utilizan variedades lingüísticas de cualquier tipo - lenguas, dialectos, sociolectos, registros, entre otros- con funciones diferentes.

En la ranchería El Pasito de la Media Guajira, Mejía (2011) identifica que el contacto ha propiciado situaciones de diglosia, pues los hablantes hacen uso preferencial de una lengua a partir del contexto en el que se encuentran. Sobre estos contextos diglósicos, es posible decir que en algunas comunidades el español tiene prelación frente

3. Además de español y el wayuunaiki, en la Guajira se habla árabe, kogui, ingano, entre otras lenguas propias de los otros grupos que también conviven en el territorio. 
al wayuunaiki; y en otras el wayuunaiki es la lengua de preferencia. Esta distribución de los ámbitos de uso no es equitativa y así lo afirma Boyer (1997, como se citó en Bigot, 2007): la coexistencia de dos o más lenguas en un mismo lugar no es nunca igualitaria, por lo tanto, no puede existir una diglosia «neutra» (p. 71). En consonancia con esta postura, los autores de este artículo consideran que en una situación de diglosia siempre habrá una lengua que tenga mayor dominio que la otra, y mientras los hablantes acepten esas dinámicas, la diglosia podrá mantenerse.

En los escenarios de contacto del español con las lenguas indígenas de Colombia, el español suele ser la lengua con mayores ámbitos de uso, al tener mayor prestigio y supremacía (Trillos, 2001). En La Guajira, Etxebarria (2012) resalta que el español aparece como la lengua dominante en las relaciones sociales y como la lengua oficial en ámbitos como la administración, los medios de comunicación y el comercio, a pesar de que el wayuunaiki ha sido declarado cooficial en el departamento por ordenanza 0002 de 1992, y de que en el autodiagnóstico sociolingüístico ocupa el tercer lugar en el grupo de las lenguas indígenas más vitales del país (Bodnar, 2013).

Pérez Van-Leenden (1998) plantea que «la vitalidad del wayuunaiki sigue expresándose en la existencia de monolingües aún en la malla urbana de ciudades como Riohacha» (p. 36), es decir, el uso se localiza especialmente en quienes, a pesar del contacto, permanecen hablando la lengua materna. Sin embargo, como dice Etxebarria (2012), para muchos de los bilingües wayuu, este es un período histórico de su pueblo, en el que se está produciendo la transición del mundo rural al urbano. La población monolingüe del wayuu se reconoce como la minoría que habita los resguardos o comunidades más distantes de los municipios donde se habla español, y esta condición permite que los nativos monolingües mantengan su lengua y sus tradiciones. No obstante, el foco del debilitamiento de la lengua se sitúa en las nuevas generaciones. Según el Ministerio de Cultura (2013):

Hay debilitamiento del habla en las nuevas generaciones, tal como lo muestra el hecho de que aproximadamente el $60 \%$ de los jóvenes, que por necesidad se dirigen a las ciudades y donde deben aprender una segunda lengua, hablan poco el idioma nativo y manifiestan vergüenza étnica debido a su vínculo social (p. 17).

De acuerdo con lo anterior, se asume que las generaciones jóvenes se enfrentan a la necesidad de aprender el español para desenvolverse en las actividades comerciales y académicas, razón por la cual hablar del estado de vitalidad del wayuunaiki implica concentrarse en las situaciones de bilingüismo y diglosia que se viven en algunos sectores del departamento. Además, analizar el estado del wayuunaiki requiere observar en conjunto los factores socioeconómicos y políticos que tienen lugar al interior de la comunidad, los fenómenos lingüísticos que se dan en estos escenarios; y, por supuesto, las actitudes lingüísticas de los wayuu.Pérez Van-Leenden (1998) considera que hay una población wayuu que se esfuerza en adoptar como propia la lengua española para ascender socialmente. Con respecto al riesgo en el que se encuentra esta lengua, expertos de la UNESCO (2003) plantean que:

El peligro de desaparición de una lengua puede ser el resultado de fuerzas externas [...] o puede tener su causa en fuerzas internas, como la actitud negativa de una comunidad hacia su propia lengua. A menudo las presiones internas 
tienen su origen en presiones externas, y unas y otras detienen la transmisión intergeneracional de las tradiciones lingüísticas y culturales. Muchos pueblos indígenas, asociando su condición social desfavorecida con su cultura, han llegado a creer que no merece la pena salvaguardar sus lenguas. Abandonan su lengua y su cultura con la esperanza de vencer la discriminación, asegurarse un medio de vida y mejorar su movilidad social o integrarse en el mercado mundial (p. 2).

Con esta sentencia, la UNESCO centra su atención en el lugar que ocupan las actitudes lingüísticas en la conservación de las lenguas. Las actitudes negativas hacia el sistema lingüístico se traducen en desuso de la lengua y en la creación de una conciencia de desarraigo hacia la cultura. En este escenario problemático surge la necesidad de estudiar las actitudes lingüísticas de los wayuu de Majayura, una comunidad ubicada al norte de la Falla de Oca y la Serranía de Perijá, a 25 kilómetros del municipio de Maicao, en La Guajira. Esta comunidad está conformada por casas de una planta habitadas por núcleos familiares de entre cinco y siete miembros. Según la Corregiduría, en Majayura hay hogares integrados únicamente por wayuu, otros en que todos son alijunas ${ }^{4} \mathrm{y}$ algunos en los que se presenta un mestizaje entre los nativos y criollos. Según la autoridad tradicional indígena ${ }^{5}$, el número total de indígenas wayuu de Majayura oscila entre 350 y 370, distribuidos en 80 familias. En las observaciones hechas se identificó que, aunque la mayoría de las familias son pequeñas, hay núcleos que incluyen abuelos y nietos.

En términos físicos, se observa que hay viviendas de concreto, algunas del tipo maloca y otras construidas en madera. La comunidad está organizada en calles pavimentadas, y algunas casas están situadas fuera de estas calles. Las principales actividades llevadas a cabo por los pobladores son la siembra de cultivo de palma y maíz en la Serranía del Perijá, y el comercio de productos colombianos hacia Venezuela. Los jefes del hogar suelen viajar a Maicao en busca de provisiones, mientras las mujeres se dedican al cuidado de las casas y la crianza de los hijos.

Según el reporte de la autoridad indígena, la mayoría de los wayuu que habitan esta comunidad son bilingües debido al contacto con el español, a la cercanía con el municipio de Maicao y a todas las transacciones comerciales que se llevan a cabo. Al interior de Majayura se evidencia que los pobladores usan el español cuando conversan con vecinos alijunas, cuando están en las tiendas o mercados de la población y cuando toman transporte hacia municipios aledaños. Al interior de los hogares, suele usarse el wayuunaiki, las conversaciones entre familiares también se hacen en la lengua nativa y en las labores del campo se elige una de las dos lenguas dependiendo de quiénes sean los interlocutores. En las tiendas y en las calles también se pueden presenciar algunas conversaciones entre miembros de la etnia que se dan en wayuunaiki.

En este contexto se plantea la necesidad de analizar las actitudes lingüísticas de la comunidad de Majayura hacia su propia lengua. En este artículo se describen las actitudes de los hablantes del wayuunaiki residentes

4. Los wayuu designan alijuna a la persona no indígena; alijuna kachako, alijuna krinko, alijuna tutko, son referentes de las personas del interior de Colombia, de Estados Unidos y Europa y del Oriente, respectivamente (Etxebarria, 2012).

5. Se decidió omitir los nombres propios de las autoridades y líderes indígenas para proteger sus identidades. 
en Majayura a partir el estudio de parámetros como la conciencia sociolingüística, la lealtad y el orgullo de la comunidad hacia su lengua. Este trabajo busca ser un aporte para fortalecer la identidad cultural del pueblo wayuu.

\section{Reflexión teórica en torno a las actitudes lingüísticas}

Moreno Fernández (1998) plantea que las actitudes lingüísticas son percepciones sociales hacia las lenguas, las variedades y los usos lingüísticos de una comunidad. De esta manera, se cree que las actitudes son sociales, se comparten y constituyen uno de los criterios centrales para determinar la pertenencia a una comunidad de habla. Blas Arroyo (2004) destaca que «puede hablarse de las posturas críticas y valorativas que los hablantes realizan sobre fenómenos específicos de una lengua o, incluso, sobre variedades y lenguas concebidas como un todo» (p. 322). Las actitudes lingüísticas constituyen los juicios y evaluaciones que hacen los hablantes sobre las lenguas propias y ajenas.

Bouchard, Giles y Sebastian (2000) plantean que la actitud lingüística es, en un sentido amplio, cualquier indicio afectivo, cognitivo o de comportamiento evaluador hacia variedades de lenguas o hacia sus hablantes. Esta definición expande lo expresado en Moreno Fernández en cuanto incluye los componentes de la actitud propuestos desde la psicología social, como los conocimientos, las creencias, los estados de ánimo, los sentimientos y las emociones de los hablantes con respecto a cualquier variedad o fenómeno lingüístico.

En esta investigación se asume la actitud lingüística como una postura evaluadora hacia la lengua, que se manifiesta socialmente y que constituye un criterio fundamental para la delimitación de una comunidad de habla. También se acoge la postura mentalista, la cual incluye los componentes emotivo, cognitivo y conativo ${ }^{6}$ teniendo en cuenta que las actitudes dependen de diferentes factores que, eventualmente, determinan tanto la función como el uso de la lengua en el contexto sociocultural (Baker, 1992). En este trabajo se hace una diferenciación entre las actitudes positivas asociadas a sentimientos de identidad, de preferencia, de lealtad y de orgullo hacia la lengua; y las actitudes negativas asociadas a sentimientos de indiferencia, menosprecio, rechazo y abandono de la lengua.

Según Makuc (2011), el componente emotivo supone la valoración y evaluación de un sistema lingüístico y sus variedades al interior de la comunidad de habla, a través de los sentimientos expresados positiva o negativamente hacia la lengua. López Morales (2004) incluye aquí las emociones que suscita el objeto en el individuo. Este componente también se fundamenta en los juicios de valor sobre las características del habla y la asociación con rasgos de identidad: etnicidad, lealtad, valor simbólico, orgullo; así como en el sentimiento de solidaridad con el grupo de pertenencia (Gómez, 2002). Este último componente se analiza a partir de las preferencias de los hablantes con respecto al uso del wayuunaiki, el grado de identidad cultural con la comunidad, la lealtad y el orgullo lingüístico.

El componente cognitivo se refiere a los conocimientos, las creencias y los prejuicios de los hablantes con

6. En búsqueda de la brevedad y la pertinencia de los componentes emotivo y cognitivo, el componente conativo se analizará en una próxima publicación. 
respecto a su lengua o variedad (Gómez, 2002). Morales (1996) incluye aquí tanto las creencias como las ideas y los pensamientos de la persona acerca del objeto, que en este caso es la lengua propia. Esta postura se conecta con lo que sostienen Couper, Guethals, Olson y Worchel (2002) cuando afirman que la información cognoscitiva proviene de evaluaciones de los objetos fundamentadas en el conocimiento y las ideas que se tienen sobre ellos. En este estudio, se comprenden aspectos relacionados con el reconocimiento de la variación diatópica del sistema lingüístico y el grado de prestigio que los hablantes le asignan a su lengua. De acuerdo con Gómez (2002), este componente conforma en gran medida la conciencia sociolingüística de los hablantes, por tanto, se incluyen aquí indicadores de este parámetro.

\section{Metodología}

Esta investigación se inscribe en el enfoque cualitativo, que estudia la realidad en su contexto natural tal como sucede e intenta interpretar los fenómenos de acuerdo con los significados que tienen para los implicados (Rodríguez, Gil \& García, 1996). En este trabajo se sigue el método etnográfico, una de las metodologías características del enfoque cualitativo. Guber (2011) plantea que, en la etnografía, «el investigador se propone interpretar-describir una cultura para hacerla inteligible ante quienes no pertenecen a ella» (p. 19). En este sentido, el estudio se fundamenta en la descripción e interpretación de las creencias, saberes, sentimientos y comportamientos lingüísticos de los nativos wayuu de Majayura, a partir del análisis de los significados culturales y las actitudes expresados en los relatos y prácticas de los nativos, y considerando que, en estos estudios, los actores son los privilegiados a la hora de expresar el sentido de su vida y su cotidianidad (Guber, 2011)..

Según Restrepo (2016), en la etnografía las descripciones que se logran son comprensiones bien situadas y específicas porque «dan cuenta de formas de habitar e imaginar, de hacer y de significar el mundo» (p. 17). Hay que tener en cuenta que en tanto situadas, las acciones y los significados que tanto el investigador como los grupos sociales construyen, dependen de sus propios lugares y trayectorias, de las relaciones sociales y culturales en las que se encuentran inscritos y de las tensiones que emergen y se viven (Restrepo, 2016). En el trabajo etnográfico desarrollado en Majayura se indagó acerca de aquellos significados que construyen los wayuu y que sustentan sus actitudes lingüísticas hacia el wayuunaiki, en un escenario de contacto permanente con el español.

El acercamiento a la comunidad y el trabajo de campo se facilitó debido a que uno de los investigadores es oriundo del municipio de Maicao en La Guajira, por lo que ha estado gran parte de su vida rodeado de la etnia wayuu, y ha logrado establecer diálogos frecuentes con autoridades y líderes indígenas de Majayura. De hecho, una de las lideresas hizo acompañamiento durante algunas etapas de observación, ayudó a socializar el proyecto entre los pobladores, e incluso identificó y contactó a los nativos con mayor reconocimiento social y cultural en la comunidad ${ }^{7}$.

7. Es necesario agradecer a toda la comunidad de Majayura, especialmente a la líder, por su apoyo permanente durante la ejecución de este proyecto. A quienes fueron entrevistados se les solicitó su colaboración, y ellos de forma voluntaria y solícita aceptaron. Sin duda, la participación de la líder resultó decisiva en la creación del ambiente propicio para el trabajo de campo. 
En diálogo con las autoridades indígenas se supo que en Majayura hay entre 350 y 370 wayuu distribuidos en 80 familias. Los nativos se reconocieron como pertenecientes al clan Apüzhana. La mayoría de los wayuu residentes en Majayura son bilingües debido a la cercanía con el municipio de Maicao en el que todas las transacciones comerciales se llevan a cabo en español (Líder indígena, comunicación telefónica, 17 de julio de 2019). El bilingüismo se presenta por el contacto histórico con el español desde la fundación de la comunidad y las relaciones interétnicas que se viven allí.

Para la recolección de los datos se trabajó con dos técnicas: la entrevista semidirigida — el tipo de entrevista más frecuente en los estudios de actitudes lingüísticas (González, 2008) — y la observación participante. La entrevista resultó ser la técnica adecuada para lograr acceder a esas formas de significar de la comunidad porque permitió sistematizar los datos a partir de las categorías propuestas por los nativos. En la descripción etnográfica no se toma en cuenta solo lo que la gente hace, sino también lo que dice que hace (Restrepo, 2016), y una forma idónea de indagar sobre ello es a través de la entrevista. Por eso, se incluyeron preguntas abiertas, con el fin de acceder a las explicaciones que los informantes ofrecen en los puntos más relevantes (González, 2008). A partir de estas consideraciones, se entrevistó a 14 nativos, quienes fueron contactados a través del muestreo de bola de nieve generado entre líderes de la comunidad. Los participantes fueron seleccionados de acuerdo con su edad, residencia y reconocimiento social. —Además, se procuró acudir a aquellos pobladores que fueran adultos bilingües wayuu-español, con residencia y reconocimiento social en Majayura-. En este tipo de muestreo no probabilístico, se identifican los casos de interés a partir de un informante clave que conozca a posibles candidatos (Martínez-Salgado, 2012, p. 616). Los participantes fueron hombres y mujeres que se ubican académicamente entre la formación básica primaria y secundaria, divididos en dos grupos etarios: el primero, de 18 a 35 años; y el segundo, de 35 años en adelante.

Se diseñó un cuestionario de doce preguntas dividas en tres grupos de cuatro preguntas, cada grupo relacionado con un componente de las actitudes. Las entrevistas estaban enfocadas en aspectos como las preferencias de los hablantes con respecto al uso de wayuunaiki; la conciencia sociolingüística, el grado de identidad cultural con la comunidad, la lealtad y el orgullo lingüístico. Por ello, se incluyeron preguntas como ¿a usted le gusta más el wayuunaiki o el español?, ¿cómo le parece que hablan el wayuunaiki en esta comunidad?, ¿qué lengua habla mientras está en el centro de Maicao?, ¿cómo se siente cuando un alijuna le pide que hable en wayuunaiki?

La observación participante permitió registrar y describir las interacciones comunicativas de los indígenas wayuu en su propio territorio, teniendo en cuenta que el objetivo de esta técnica es, según Guber (2011), «detectar las situaciones en que se expresan y generan los universos culturales y sociales en su compleja articulación y variedad» (p. 52). La misma autora plantea que la aplicación de este tipo de observación supone que la presencia directa del investigador frente a los hechos cotidianos de la población garantiza por sí sola, «la confiabilidad de los datos recogidos y el aprendizaje de los sentidos que subyacen a dichas actividades» (p. 52).

Para la aplicación de esta técnica se elaboraron guías de observación en las que se registró y describió el área física de la comunidad, los ambientes sociales y laborales, y la lengua de uso en diferentes contextos. Dichos 
aspectos revelaron situaciones de comunicación que incidieron en el análisis de las actitudes lingüísticas de los wayuu. Teniendo presente que, de acuerdo con Guber (2011), «el único medio para acceder a esos significados que los otros negocian e intercambian es la vivencia» (p. 55), se emprendieron labores de socialización como visitar los hogares y los espacios de trabajo de los nativos para lograr un registro sistemático de sus actitudes y comportamientos en diversos contextos comunicativos. Este proceso de participación tuvo lugar durante el segundo semestre del 2018 y el primero de 2019.

\section{Actitudes lingüísticas hacia el wayuunaiki: análisis de los datos}

En este análisis se incluyen los componentes afectivo y cognitivo de las actitudes de los wayuu hacia su lengua nativa, teniendo en cuenta aspectos como la conciencia sociolingüística — prestigio de la variedad propia y reconocimiento de la variación - y los sentimientos de lealtad y orgullo de la comunidad de Majayura hacia su lengua.

\subsection{Conciencia sociolingüística}

La conciencia sociolingüística es definida por Moreno Fernández (1998) como el reconocimiento que hacen los hablantes acerca de los usos lingüísticos característicos o predilectos de su comunidad, los fenómenos de variación y los usos lingüísticos que consideran correctos o adecuados a cada circunstancia. Zamora (2015) relaciona esta conciencia lingüística con el conocimiento acerca de las variantes dialectales de una lengua y la posibilidad de marcar diferencias entre la forma de hablar en una y otra zona. En este artículo se analiza esta noción a partir del prestigio lingüístico y el reconocimiento de fenómenos de variación.

\subsubsection{Prestigio lingüístico}

Hernández-Campoy (2004) define el prestigio como «un comportamiento lingüístico motivado por las actitudes sociales adoptadas ante determinadas formas lingüísticas», producto de la estima que adquieren algunas variedades, «como consecuencia de una reputación adquirida o atribuida, que es totalmente subjetiva» (p. 41). En este tópico se indagó sobre la manera en la que los nativos evalúan o califican la forma en la que los miembros de su comunidad hablan el wayuunaiki. Se observaron fundamentalmente dos posturas: por un lado, están quienes consideran que lo hablan bien o normal; y, por otro lado, quienes expresan que en su comunidad no hablan su lengua porque se avergüenzan de ella. A continuación, algunas de las respuestas de los nativos inscritos en la primera postura: 
Hablamos igual. Normal. (MAJAY0912H) ${ }^{8}$

Bien igual, igual que cualquiera wayuu que ande por ahí. (MAJAY1011H)

Normal como todo lo de otro la'o, de Maicao. (MAJAY1111H)

Bien, lo hablan bien. (MAJAY1111H)

Cuando los hablantes evalúan su habla como buena, probablemente se refieren a su grado de adecuación frente a sus necesidades comunicativas. De hecho, en la comunidad se observa que algunas veces las conversaciones entre wayuu que se dan en las tiendas y en las calles son en wayuunaiki, y es probablemente en estos escenarios que se abordan temas personales o de intereses de la etnia, lo cual lleva a que los hablantes prefieran su lengua. Rodríguez (1988) plantea que «ninguna forma, palabra o estructura lingüística es por sí misma buena o mala, ni peor ni mejor que cualquier otra. Simplemente es más o menos adecuada» (p. 69). Hernández-Campoy (2004) plantea que los juicios de valor sobre la corrección y adecuación de las variedades lingüísticas son más la expresión de actitudes sociales frente al grado de prestigio de esas variedades, que una valoración de sus características lingüísticas.

En la segunda postura se encontró que los hablantes asumieron que se les estaba preguntando por el uso de la lengua en Majayura. Esa interpretación dio paso a que sostuvieran que a unos nativos les genera vergüenza o pena hablar wayuunaiki al interior de la comunidad. Los entrevistados dijeron:

\begin{abstract}
Algunoh son muy pa' decir, o sea no sé como que le da pena hablá' su lenguaje, y le da pena con el arte, lo que tiene que ver con el wayuu, le da como pena entonces, la verdad para mí, a mí no me da pena, eso soy, soy lo que soy y mis padres son wayuu, soy orgullosa de que yo sea wayuu, de que soy yo lo, de lo que yo soy, no soy ni alijuna ni, soy wayuu y me siento orgullosa de ser wayuu. (MAJAY0112M)
\end{abstract}

No lo hablan mucho, prefieren el español que el wayuu. (MAJAY1411H)

Bueno aquí hay a veces hay wayuu que no les gusta casi hablar el wayuunaiki, aquí eso es rara persona que uno le hable wayuunaiki y ella le responda en wayuunaiki, a veces cuando uno les dicen que le hablen wayuunaiki la única manera que ellas hablan, que las personas hablan. (MAJAY0321M)

En estos discursos es evidente la autodesvalorización de la propia lengua, que en este caso se ha generalizado por el lugar y el grado de prestigio de la misma. Cotacachi (2017) explica que la desvalorización de las lenguas nativas, y la vergüenza de hablarlas, ha ocasionado que las familias indígenas privilegien el uso del idioma dominante como mecanismo de adaptación al contexto social dominante. Este hecho tiene que ver con el prestigio y la supremacía del español sobre las lenguas indígenas (Trillos, 2001), que ha influido en la formación de actitudes negativas entre los wayuu de Majayura.

8. Este código corresponde a MAJAY: Comunidad, Majayura / 09: número del orden del entrevistado / 1: grado de instrucción: básica primaria / 2: edad /: 36 años en adelante / H: sexo, hombre. Cada uno de los códigos se define en la tabla de abreviaturas que aparece al final del artículo. 


\subsubsection{Reconocimiento de variedades}

Los resultados revelan que mientras una parte de los nativos encuentra variación diatópica en el wayuunaiki, otra parte sostiene que no hay diferencias. Aquí se puso la atención en quienes afirmaron que hay variación y señalaron los siguientes ejemplos como evidencia:

Hay palabras que por lo menos aquí lo decimos de una forma y allá lo dicen de otra pero con la diferencia que, o sea, no es no lo pronuncia así como nosotros lo pronunciamos. Una palabra, como por decir ariuka por aquí eh por allá aliuka con la /ele/ y por acá a veces con la /ere/, eso también es así como en La Alta en La Media y en La Baja, que no, que no me pronuncian así, siempre diferencian lo, las pronunciaciones en la forma en pronunciarla. (MAJAY0321M)

Sí, por ejemplo, el de aquí de La Guajira o sea de acá de esta zona tenemoh otro acento y pa' 'llá pa' Cuatro Vías tienen su otro acento también y pa' los venezolanos también tienen su acento ahí, este, a veces elloh pronuncian o sea casi igual, casi la misma, pero tiene que a veces una letra de más o una menos entonces pero, uno lo entiende ya sabemos que... (MAJAY0112M)

Sí, en cierta parte porque a veces el wayuunaiki de allá a veces como un acento, como deci’ no sé, tienen un acento, pero es lo mismo, pero tiene un acento diferente un poquito diferente que otro. Es como decir los de Maracaigo y los de Colombia, de Maicao si hablan diferente acento, ya saben que... que estos son maracuchos y así. (MAJAY1111H)

Como puede notarse, hay conocimiento por parte de los nativos sobre la variación del wayuunaiki, tanto al interior de la región como fuera del país. Existen fundamentalmente dos variedades dialectales de esta lengua, el «abajero»y el «arribero», cuya diferencia no está suficientemente documentada desde una perspectiva lingüística. El wayuunaiki «arribero» se habla en winpumüin y el «abajero» en wopumüin. Ambas se diferencian fundamentalmente por «el índice de tercera persona singular no masculino j- (arribero) y sh-/s- (abajero): /shein/ vestido /jushein/ /sushein/ su vestido (de ella).» (Pérez Van-Leenden, 2000, p. 793).

En lo que respecta a la lengua de los wayuu, se localizan fenómenos de variación determinados por el factor geográfico, que los hablantes de Majayura reconocen sobre todo desde el plano prosódico cuando señalan que en territorios de la Alta Guajira y en Venezuela el acento o la pronunciación son distintos. La prevalencia de expresiones del tipo «aquí lo decimos de una forma y allá lo dicen de otra» y «es así como en La Alta, en La Media y en La Baja, que no se pronuncian así, siempre diferencian las pronunciaciones» indica que los hablantes reconocen variaciones diatópicas en el wayuunaiki. Esta variación es circunscrita por Santiago (2015) a aquellos fenómenos fonético-fonológicos, gramaticales, léxicos, pragmáticos y discursivos que son producto de la variación geolectal.

Los nativos reconocen la variación del wayuunaiki hablado en Colombia y en Venezuela sobre todo en el nivel fonético, como se evidencia en el siguiente discurso de un hablante:

Una palabra, como por decir ariuka por aquí, eh, por allá aliuka con la /ele/ y por acá a veces con la /ere/ eso también es así como en La Alta en La Media y en La Baja, que no, que no me pronuncian así. (MAJAY0321M) 
El hablante introduce un fenómeno de variación definido como rotacismo9 que consiste en la neutralización de la consonante lateral alveolar /1/ por la vibrante simple alveolar /r/ que en español se presenta generalmente en posición posnuclear o de distensión silábica (Aleza, 2010). En el ejemplo citado, el rotacismo se presenta en posición de ataque silábico y entre vocales, pero no se ha investigado lo suficiente sobre el fenómeno en este contexto. Flores (1996) referencia un estudio de Álvarez (1994) sobre el cambio prenuclear de /1/ a [r] en la lengua guajira, y Oquendo $(1996 ; 2002)$ analiza casos de neutralización de las líquidas pre y posnucleares con 150 hablantes bilingües wayuu asentados en el eje fronterizo colombovenezolano. Oquendo y Domínguez (2006) explican que «cuando el hablante bilingüe guajiro habla español, con frecuencia cambia /r/ por /1/ en posición final de sílaba ${ }^{10}$, a semejanza de lo que ocurre en el español de la comunidad lingüística del Caribe» (p. 7). También se da el fenómeno contrario — como puede verse en el ejemplo de arriba— donde se sustituye la lateral por la vibrante. De ese modo el hablante bilingüe wayuu transpone el fenómeno lingüístico a su lengua nativa.

Es necesario mencionar que el contacto de lenguas que se vive en Majayura genera los espacios para que los fenómenos de la lengua dominante se traspongan al wayuunaiki de algún modo. Esto último es posible gracias a los ámbitos de uso social y público en los que es imprescindible hablar el español para comunicarse o acceder a algún servicio. En las observaciones hechas sobre las formas de interacción de la comunidad, se notó que los wayuu de Majayura hacen uso del español en las calles de la comunidad, mientras van a la tienda a comprar algún producto. También lo usan en el ámbito del transporte hacia el municipio de Maicao. Como muchos de sus vecinos son alijunas, los wayuu usan el español para dialogar con ellos.

Respecto al reconocimiento de variedades se concluye que los hablantes tienen conocimiento sobre algunas diferencias entre el wayuunaiki hablado al interior del departamento de La Guajira, y el hablado en Venezuela y Colombia. Los nativos asocian la variación con fenómenos a nivel fonético — adición, sustracción o neutralización de fonemas - , pero, sobre todo, con rasgos suprasegmentales asociados al acento y la pronunciación.

\subsection{La lealtad lingüística y el orgullo de los wayuu hacia su lengua}

En este componente se indagó sobre la preferencia de la lengua nativa frente al español. Por ello, se formularon varias preguntas sobre lealtad hacia el wayuunaiki. Los wayuu expresaron preferencia por su lengua debido a que consideran que al ser propia del territorio donde habitan, no deben cambiarla. En sus discursos expresan:

El wayuunaiki porque yo vivo aquí, en territorio wayuu. ¿Ya? el lenguaje de nosotros lo aprendimos... (MAJAY0612H)

A mí me gusta más el wayuunaiki porque ese es mi lenguaje y mi cultura y porque yo soy wayuu, no debo de

9. La neutralización también puede darse de forma contraria, se pasa de /r/ a /1/ y se conoce como lambdacismo. Congosto (2002) cita ejemplos como alcabuz en lugar de arcabuz y añir en lugar de añil.

10. En este punto se refiere al lambdacismo. 
cambiar mi lenguaje. (MAJAY0112M)

El wayuunaiki no lo puedo decir que no me gusta porque ya ese es la tradición mía. Ya eso es herencia mía, ya eso no lo puedo rechazar. (MAJAY1321H)

En estas respuestas, los nativos parecen sentirse identificados con su lengua, un hecho que promueve la lealtad lingüística, definida por Moreno Fernández (1998) como una reacción que lleva a los individuos a conservar la lengua amenazada y a convertirla en un símbolo social, en una causa. El autor vincula la lealtad con el afecto que se siente por la lengua materna, lo que garantiza su mantenimiento ante la posibilidad de un cambio. En esta situación de contacto, los hablantes expresan lealtad hacia el wayuunaiki debido a que consideran que es un elemento identitario que representa la herencia cultural del grupo étnico y marca la adscripción a lo que ellos denominan como «territorio wayuu».

En el contexto wayuunaiki-español, la lealtad lingüística es un recurso emocional que apoya la conservación de la identidad de un grupo tradicionalmente dominado por una comunidad de mayor poder económico y social, la hispanohablante. Los wayuu de Majayura todavía reaccionan a favor de su lengua nativa. El hecho de que interactúen entre ellos en wayuunaiki en escenarios públicos como la tienda o la calle da cuenta de que constituye un elemento de vinculación y de resistencia, y estas dinámicas probablemente han influido en que la lengua haya logrado mantener su vitalidad.A los hablantes también se les planteó la posibilidad de usar el wayuunaiki como lengua exclusiva en la comunidad. La mayoría señaló que está de acuerdo con que se hable tanto su lengua nativa como el español. En sus palabras:

No, solo wayuunaiki tampoco. Ah, porque no, porque estamo' en el poblado de alijunas también. Yo no quisiera que mis hijos solamente hablen wayuunaiki, tienen que también hablar el español también, como uno, pué' porque yo, el día de mañana si estudian, si sean unos profesionales, trabajan dentro de los alijunas, pué, con los alijunas.

(MAJAY0612H)

Hay personas que, por ejemplo, ustedeh que son alijunas. Uno tiene que aprender eso. Porque si nosotros no aprendemos el castellano cómo nos entendemos, cómo loh entendemos a ustedeh y ustedeh a nosotros. Hay que aprender las dos, las dos lenguas. (MAJAY1111H)

Hay entre los hablantes reconocimiento de la utilidad del español para desarrollarse en contextos laborales ajenos a la comunidad. El hecho de que la enseñanza escolarizada promueva el aprendizaje del español influye en las actitudes que tienen los nativos hacia esta lengua. La mayoría de los hablantes coincidió en que le gustaría que se hablaran ambas lenguas, mientras la otra parte expresó que le gustaría hablar únicamente wayuunaiki. Un miembro de este último grupo argumentó:

Yo quisiera que los wayuu todo loh que son wayuu hablaran wayuunaiki y enseñaran sus hijos, así como nosotros acá que los hijos de nosotros nacen, o sea, ellos con su lenguaje desde pequeños, ya cuando están grandecitos aprenden a habla' cuando se juntan con los alijunas ya dejan de hablar eso, entonces ya cuando ya están crecidoh [...] ya ellos vuelven otra vez y hablan wayuunaiki porque uno leh dice a ellos que eso no tienen que olvidarse de su lenguaje. (MAJAY0112M). 
Este es el discurso de una mujer nativa que opina que todos los wayuu deberían hablar la lengua wayuunaiki y preocuparse por su enseñanza al interior de la comunidad. De acuerdo con Oquendo (1985), las mujeres se posicionan como la columna vertebral del pueblo wayuu, y por medio de la lengua se forma, se fragua, la identidad indígena wayuu. Por ello, es interesante que las nativas expresen su lealtad a la lengua a través de ese deseo de transmitirla a las actuales y futuras generaciones.

La lealtad lingüística ${ }^{11}$ se vincula con el orgullo lingüístico, que se entiende aquí como la estimación o valoración que lleva a los hablantes a sentirse satisfechos con su propia lengua (Pérez, 2016) y a no avergonzarse de su uso. Para Gundermann (2014), el orgullo representa una ideología lingüística positiva que promueve el reposicionamiento de una lengua. En Majayura, se indagó acerca de los sentimientos que le genera exponer su lengua ante alijunas. Se encontró que a los nativos no les molesta cuando una persona no perteneciente a la etnia les pide que hablen en wayuunaiki. Los wayuu se sienten orgullosos cuando les solicitan que hablen su lengua. En sus discursos señalan:

Me siento orgulloso porque ellos me están, para qué uno se va a poner a molestar, más bien los alijunas quieren aprender a hablah el wayuunaiki también. (MAJAY1212H)

No me molesta. ¿Por qué me voy a molestar? Si esa es mi lengua. (MAJAY0212M)

Más bien me enorgullezco. (MAJAY1111H)

La lengua nativa representa un valor relacionado con la identificación, la pertenencia a un grupo, la solidaridad, la lealtad y el orgullo lingüístico. Este valor integrativo se vincula con la dimensión afectiva de las actitudes lingüísticas (Zamora, 2015, p. 32). Los nativos consideran que no existen motivos para molestarse y argumentan que su lengua es un objeto de interés para las otras personas. Ellos expresan:

Si me dice enséñame a habla’ wayuunaiki [...] yo lo enseño. (MAJAY0912H)

Depende, y si es por mamarle gallo a uno, sí me molesta, si es porque quiere aprender sí, sí le puedo enseñar. (MAJAY1011H)

Más bien los alijunas quieren aprender a hablah el wayuunaiki también. (MAJAY1212H)

Yo me imagino yo que el alijuna quisiera aprender a hablar el wayuunaiki y quisiera entenderme cuando yo le hablo en wayuu. (MAJAY0821M)

La expresión «yo me imagino yo que el alijuna quisiera aprender a hablar el wayuunaiki», asociada al orgullo lingüístico de los wayuu, se relaciona con la propuesta de Cotacachi (2017) de poder contribuir con la conservación de la diversidad lingüística aprendiendo alguna lengua indígena del país para facilitar el entendimiento mutuo.

11. El concepto de lealtad se contrapone al de deslealtad. Por cuestiones de espacio, aquí se define solo una parte de esta dicotomía. 
En términos generales, se evidenció un grado alto de lealtad y de orgullo hacia la lengua originaria de parte de los wayuu de Majayura. A pesar del contacto entre lenguas, existe entre los nativos preferencia por la lengua wayuunaiki. En contextos de comunicación, los hablantes muestran una actitud positiva cuando se les habla en su propia lengua, probablemente porque al ser la lengua de comunicación intraétnica, les genera seguridad y sentimientos de pertenencia.

\section{A manera de conclusión}

A partir del análisis, es posible vislumbrar desde lo cognitivo una tendencia de valoración positiva hacia el wayuunaiki en términos de conocimiento sobre la variación lingüística del wayuunaiki al interior de La Guajira y fuera del país. Los hablantes consideran que la diferencia fundamental es de acento. En cuanto al grado de adecuación de su variedad lingüística, hay quienes creen que en Majayura se habla «bien», pero una parte de la comunidad considera que los wayuu no hablan su lengua porque les da vergüenza. La postura de estos últimos plantea la necesidad de promover espacios de reconocimiento de esta lengua. Es indudable que en la comunidad el español tiene ámbitos de uso cada vez más amplios y de mayor prestigio que el wayuunaiki, un fenómeno que también se da en El Pasito (Mejía, 2011).

Cotacachi (2017) señala que, comúnmente, los indígenas privilegian el uso de la lengua dominante como mecanismo de adaptación social. En este proceso los usos de la lengua propia se reducen cada vez más, por lo tanto, el reto es lograr que las generaciones actuales se interesen por ampliar los ámbitos de uso del wayuunaiki $\mathrm{y}$, de ese modo, generen actitudes positivas hacia su lengua. Este propósito requiere de la intervención del Estado para que los derechos lingüísticos de los indígenas se concreten en la posibilidad de que sus lenguas tengan plena participación en los ámbitos jurídicos, políticos y administrativos del país (Trillos, 2001).

En el componente emotivo hay un alto grado de vinculación de los hablantes con su propia lengua: el wayuunaiki es un elemento identitario que los representa y les permite reconocerse como grupo. Los nativos aprovechan cualquier espacio en que son mayoría para usarlo y sentirse wayuu plenamente, expresan lealtad y orgullo hacia la lengua. Estas son actitudes lingüísticas positivas encaminadas a la preferencia de la lengua propia, que son sintomáticas de una conciencia de conservación. Estos resultados coinciden con los encontrados por Mejía (2011) en El Pasito y ayudan a comprender por qué el wayuunaiki es una de las lenguas indígenas más vitales y activas del país.

La realidad sociolingüística que se vive al interior de Majayura es una muestra de la resistencia indígena del departamento por preservar la lengua y la cultura wayuu. A pesar de los retos que enfrenta la comunidad en un escenario de contacto permanente con el español, la lealtad lingüística de los hablantes se refleja en el mantenimiento de la lengua propia. De acuerdo con Moreno (1998), el sentimiento de lealtad lleva a los hablantes a hacer de su lengua una causa social, un símbolo de identificación. Es por ello que, para la comunidad de Majayura, el wayuunaiki representa un elemento fundamental de pertenencia a la cultura y al territorio wayuu. 
Este estudio constituye un aporte para la comprensión de las motivaciones, deseos y aspiraciones del pueblo wayuu de preservar su lengua, su identidad y su cultura; y para que los wayuu se reconozcan entre sí y emprendan acciones a favor de sus derechos culturales y lingüísticos. Es por tanto una iniciativa que se podría contrastar con la realidad lingüística de otras comunidades de la región y de otros pueblos indígenas del país. Es necesario replicar este tipo de trabajos, a fin de asumir desde la academia la responsabilidad política de preservar la diversidad étnica y contribuir con la construcción de un escenario de paz y equidad para los grupos étnicos en el territorio nacional. 


\section{Referencias bibliográficas}

1. Aleza, M. (2010). Fonética y fonología. En Aleza, M. y Enguita, M. (Coords.), La lengua española en América: normas y usos actuales (pp. 51-94). Valencia: Universitat de València. https://www.uv.es/aleza/Cap.\%202.\%20 EA\%20Fon.pdf

2. Álvarez, J. (1994). Estudios de lingüística guajira. Maracaibo: Secretaría de Cultura de la Gobernación del Estado Zulia.

3. Andrade, L. (2016). Prácticas y actitudes lingüísticas de estudiantes kichwas en la ciudad de Quito: el caso de la Unidad Educativa Tránsito Amaguaña. Quito: Pontificia Universidad Católica Del Ecuador. http:// repositorio.puce.edu.ec/bitstream/handle/22000/11515/PR\%C3\%81CTICAS\%20Y\%20ACTITUDES\%20 LING\%C3\%9C\%C3\%8DSTICAS\%20DE\%20ESTUDIANTES\%20KICHWAS\%20EN\%20LA\%20CIUDAD\%20DE\%20QUITO\%20EL\%20CASO\%20DE\%20LA\%20UNI.pdf?sequence=1\&isAllowed=y4. Baker, C. (1992). Attitudes and Language. Clevedon: Multilingual Matters Ltd.

5. Bigot, M. (2007). Los aborígenes qom en Rosario. Contacto lingüístico-cultural, bilingüismo, diglosia y vitalidad etnolingüistica en grupos aborígenes «qom» tobas asentados en Rosario. Rosario: UNR Editora Universidad Nacional del Rosario.6. Blas Arroyo, J. (2004). Sociolingüística del español. Desarrollos y perspectivas en el estudio de la lengua española en contexto social. Madrid: Ediciones Cátedra, S. A. https://ebuah.uah.es/dspace/ handle/10017/24617

7. Bodnar, Y. (2013). Estudio comparativo de la vitalidad lingüística de 14 pueblos de Colombia realizado mediante una encuesta (autodiagnóstico sociolingüístico). Notas de Población, XI (97), 249-293. https://repositorio. cepal.org/bitstream/handle/11362/35947/np97249293_es.pdf?sequence=1\&isAllowed=y

8. Bouchard, R., Howard, G. \& Richard, S. (2000). Una perspectiva integrativa para el estudio de actitudes hacia la variación lingüística. En Lastra, Y. (Ed.), Estudios de Sociolingüística (pp. 491-511). México: Instituto de Investigaciones Antropológicas-UNAM.

9. Boyer, H. (1997). Conflit d'usages, conflit d'images. En H. Boyer (Ed.), Plurilinguisme: « contact» ou « conflit » de langues? (pp. 9-35). Paris : L’Harmattan.

10. Congosto, Y. (2002). Aportaciones a la historia lingüística de las hablas andaluzas (siglo XVII). Descripción de una sincronía. Sevilla: Universidad de Sevilla. https://books.google.com.mx/books?id=4xSFe3KstnMC\&p$\mathrm{g}=\mathrm{PA} 101 \& \mathrm{lpg}=\mathrm{PA} 101 \& \mathrm{dq}=$ neutralizaci $\% \mathrm{C} 3 \% \mathrm{~B} 3 \mathrm{n}+\mathrm{o}+$ confusi $\% \mathrm{C} 3 \% \mathrm{~B} 3 \mathrm{n}+\mathrm{de}+$ las + consonantes $+1 \% \mathrm{C} 3 \% \mathrm{AD}-$ quidas+en+Espa $\% \mathrm{C3} \% \mathrm{~B} 1$ ol\&source=bl\&ots=VcNzEb9w7n\&sig=ACfU3U1PwPMLwYJZx7u2nuDrwI3PJ1KUwg\&hl=es\&sa=X\&ved=2ahUKEwi55_Wu6vfnAhVBnKwKHV_yBysQ6AEwA3oECAkQA$\mathrm{Q} \# \mathrm{v}=$ onepage \&q=neutralizaci\%C3\%B3n\%20o\%20confusi\%C3\%B3n\%20de\%201as\%20consonantes $\% 20$ $1 \% \mathrm{C} 3 \%$ ADquidas\%20en $\% 20$ Espa $\% \mathrm{C} 3 \% \mathrm{~B} 1 \mathrm{ol} \& \mathrm{f}=$ false

11. Congreso de la República de Colombia (1991). Constitución política de Colombia. Bogotá: Editorial Unión 
Ltda..12. Couper, J., Guethals, G., Olson, J. \& Worchel, S. (2002). Psicología social. México: Thomson.

13. Cotacachi, D. (2017). Hablar un idioma indígena: ¿orgullo o vergüenza? https://blogs.iadb.org/igualdad/es/ hablar-un-idioma-indigena-orgullo-o-verguenza/

14. DANE (2019a). Pueblo wayúu. Resultados del censo nacional de población y vivienda 2018. https://www. dane.gov.co/files/censo2018/informacion-tecnica/presentaciones-territorio/190816-CNPV-presentacion-Resultados-Guajira-Pueblo-Wayuu.pdf

15. DANE (2019b). Resultados del censo nacional de población y vivienda 2018. https://www.dane.gov.co/files/ censo2018/informacion-tecnica/presentaciones-territorio/190816-CNPV-presentacion-La-Guajira-Riohacha.pdf 16. Etxebarria, M. (2012). Bilingüismo y realidad sociolingüística de la lengua del grupo wayuu en el caribe colombiano. Anuario del Seminario de Filología Vasca Julio de Urquijo (ASJU), XLVI-2, 271-293. https://www.ehu. eus/ojs/index.php/ASJU/article/viewFile/13458/12052

17. Fishman, J. (1967). Bilingualism with and without Diglossia; Diglossia with and without Bilingualism. Journal of Social Issues, 23, 29-38.

18. Flores, C. (1996). La evolución fonológica del español: algunos problemas y posibles soluciones. Lengua y Habla, Vol. 1-2, 20-31. http://erevistas.saber.ula.ve/index.php/lenguayhabla/article/view/3549/3437

19. Gimeno Menéndez, F. (2006). Sociolingüística histórica: el proceso de formación de las lenguas románicas. En J. L. Blas Arroyo, M. Casanova, S. Fortuño, y M. Porcar (Eds.), Estudios sobre lengua y sociedad (pp. 33-80). https://books.google.com.mx/books?id=CxZ_zH44PVkC\&pg=PA33\&dq=Socioling\%C3\%BC\%C3\%ADstica + hist $\%$ C3\%B3rica:+el + proceso + de + formaci $\% \mathrm{C} 3 \% \mathrm{~B} 3 \mathrm{n}+\mathrm{de}+\mathrm{las}+$ lenguas + rom $\% \mathrm{C} 3 \% \mathrm{~A} 1 \mathrm{nicas} \& \mathrm{hl}=\mathrm{es} \& \mathrm{sa}=\mathrm{X}-$ \&ved=0ahUKEwie37fC9KDpAhVSI6wKHV-fADcQ6AEIJzAA\#v=onepage\&q=Socioling\%C3\%BC\%C3\%ADstica\%20hist\%C3\%B3rica\%3A\%20el\%20proceso\%20de\%20formaci\%C3\%B3n\%20de\%20las\%20 lenguas $\% 20 \mathrm{rom} \% \mathrm{C} 3 \% \mathrm{~A} 1$ nicas $\& \mathrm{f}=$ false

20. Gómez, J. (2002). Lenguas en contacto y actitudes lingüísticas en la comunidad valenciana. En Blas Arroyo, J., Casanova, M., Fortuño, S. y Porcar, M. (Eds.), Estudios sobre lengua y sociedad (pp. 53-86). https://books. google.com.co/books?id=PzDimeUxlOwC\&pg=PA53\&dq=Lenguas + en + contacto $+y+$ actitudes + ling\%C3\%B$\mathrm{C} \% \mathrm{C} 3 \%$ ADsticas + en + la + comunidad + de + Valencia\&hl=es\&sa=X\&ved=0ahUKEwjszd340YvmAhXs01kKHUQrBT0Q6AEIQTAD\#v=onepage \&q= conciencia\%20\&f=false

21. González, J. (2008). Metodología para el estudio de las actitudes. Actas del XXXVII Simposio Internacional de la Sociedad Española de Lingüistica (SEL). http://www.unav.es/linguis/simposiosel/actas

22. Guber, R. (2011). La etnografía: método, campo y reflexividad. Argentina: Siglo xxi Editores.

23. Gundermann , H. (2014). Orgullo cultural y ambivalencia: actitudes ante la lengua originaria en la sociedad mapuche contemporánea. Revista de Lingüistica Teórica y Aplicada, 52(1), 105-132. https://dx.doi.org/10.4067/ s0718-4883201400010000624. Guerreiro, Y. Alviárez, L. y Sánchez, A. (2010). Una aproximación al estudio de las construcciones interrogativas en wayuunaiki/guajiro. Revista de Multiciencias, 10(1), 21-28. https://www. redalyc.org/pdf/904/90415596004.pdf 
25. Hernández-Campoy, M. (2004). El fenómeno de las actitudes y su medición en sociolingüística. Revista de Estudios Filológicos, 8, 29-56. https://www.um.es/tonosdigital/znum8/portada/monotonos/04-JMCAMPOYa.pdf 26. Landaburu, J. (2004-2005). Las lenguas indígenas de Colombia: presentación y estado del arte. Amerindia, 29/30, 3-22. https://www.vjf.cnrs.fr/sedyl/amerindia/articles/pdf/A_29-30_00.pdf

27. López Morales, H. (2004). Sociolingüistica. Madrid: Gredos.

28. Makuc, M. (2011). La actitud lingüística en la comunidad de habla de Magallanes: aproximación a sus componentes básicos. Magallanía, 39(2), 105-111.

29. Martínez-Salgado, C. (2012). El muestreo en investigación cualitativa. Principios básicos y algunas controversias. Ciência \& Saúde Coletiva, 17(3), 613-619. http://www.scielo.br/pdf/csc/v17n3/v17n3a06.pdf

30. Mejía, P. (2011). Situación sociolingüística del wayuunaiki: ranchería El Pasito. Bogotá: Universidad Nacional de Colombia. http://www.bdigital.unal.edu.co/5275/1/448197.2011.pdf

31. Ministerio de Cultura de la República de Colombia (2013). Diversidad lingüística en Colombia: muchas voces, resistencia cultural y agenda de nación. Dossier para la representación de Colombia en el Smithsonian Folklife Festival. http://www.mincultura.gov.co/areas/poblaciones/noticias/Documents/Dossier\%20Representaci\%C3\%B3n\%20Colombia\%20Smithsonian\%20Folklife\%20Festival.pdf

32. Ministerio del Interior. República de Colombia (2010). Caracterización pueblos indígenas. Pueblo Wayúu. http://www.mincultura.gov.co/prensa/noticias/Documents/Poblaciones/PUEBLO\%20WAY\%C3\%9AU.pdf 33. Morales, J. (1996). Psicología social. Madrid: McGraw-Hill.

34. Moreno Fernández, F. (1998). Principios de sociolingüística y sociología del lenguaje. Barcelona: Ariel. 35. Observatorio del Programa Presidencial de Derechos Humanos y DIH (2013). Diagnóstico de la situación del pueblo indígena Wayúu. http://historico.derechoshumanos.gov.co/Observatorio/Documents/2010/ DiagnosticoIndigenas/Diagnostico_WAY\%C3\%9AU.pdf.

36. Oquendo, L. (1985). El grito de eirü'kú: uso y aplicabilidad de la terminología de parentesco por los miembros de la sociedad guajira. (Tesis de Maestría). Maracaibo: Universidad del Zulia.

37. Oquendo, L. (1996). La inestabilidad de las líquidas y el cambio vocálico en lenguas en contacto: guajiroespañol. Ponencia leída en la XLVI Convención Anual de la AsoVAC. Barquisimeto: UCLA-UPELUNEXPO. https://www.academia.edu/40165594/La_inestabilidad_de_las_1\%C3\%ADquidas

38. Oquendo, L. (2002) La inestabilidad de las líquidas y el cambio vocálico en las lenguas en contacto guajiroespañol. (mimeografiado).

39. Oquendo, L. \& Domínguez, M. (2006). Género, etnia y actitudes lingüísticas en hablantes bilingües wayuu. ALED, 6(1), 5-20. file:///C:/Users/Lenovo/Downloads/215-848-1-PB.pdf

40. Pérez Van-Leenden, F. J. (1998). Wayuunaiki: estado, sociedad y contacto. Riohacha, Maracaibo: Universidad de la Guajira y La Universidad del Zulia.

41. Pérez Van-Leenden, F. J. (2000). Lenguas aborígenes de la Península de la Guajira. En González, M. y Rodríguez, M. (Eds.), Lenguas indígenas de Colombia: una visión descriptiva (pp. 793-794). Bogotá: Instituto 
Caro y Cuervo.

42. Pérez, L. (2016). Las actitudes lingüísticas de los jóvenes hispanos de Montreal. Lengua y Migración, 8(2), 105-132. http://lym.linguas.net/Download.axd?type=ArticleItem\&id=168

43. Ramírez, M. (2019, agosto 22). La Guajira y el pueblo wayuu en el censo 2018. Tüü Pütchika-La Palabra. https:/www.tuuputchika.com/2019/08/22/la-guajira-y-el-pueblo-wayuu-en-el-censo-2018/

44. Restrepo, E. (2016). Etnografia: alcances, técnicas y éticas. Bogotá: Envión editores. http://www.ramwan. net/restrepo/documentos/libro-etnografia.pdf.45. Rodríguez, G.; Gil, J. y García, E. (1996). Metodología de la investigación cualitativa. Ed. Aljibe, Málaga, España. http://www.academia.edu/download/38185394/ investigacioncualitativa.doc

45. Rodríguez, G. (1988). Problemas que plantea la enseñanza de lengua materna. Lexis, XII, 1, 69-82. http:// revistas.pucp.edu.pe/index.php/lexis/article/view/5443/5440

46. Santiago, X. (2015). Los métodos, ¿modelos de lengua? El tratamiento de la variación diatópica, diastrática y diafásica en algunos manuales de ELE. (Tesis de Maestría). Barcelona: Universidad Autónoma de Barcelona. https://ddd.uab.cat/pub/trerecpro/2015/hdl_2072_257386/Santiago_Andres_Xavier_TFM.pdf

47. Soler, S. (1999). Conductas y actitudes lingüísticas de la comunidad indígena Inga ante el español y el inga. THESAURUS, LIV, 3, 911-979. Centro Virtual Cervantes. https:/cvc.cervantes.es/lengua/thesaurus/pdf/54/ TH_54_003_233_0.pdf.

48. Tovar, A. (1986). Las lenguas arahuacas: hacia una delimitación y clasificación más precisa de la familia arahuaca. Bogotá: Instituto Caro y Cuervo.

49. Trillos, M. (2001). Por una educación para la diversidad. Nómadas, 15, 162-177. https://www.redalyc.org/ pdf/1051/105117927015.pdf

50. UNESCO (2003). Vitalidad y peligro de desaparición de las lenguas. Grupo especial de expertos sobre las lenguas en peligro convocado por la Unesco. http://www.unesco.org/new/fileadmin/MULTIMEDIA/HQ/CLT/ pdf/LVE_Spanish_EDITED\%20FOR\%20PUBLICATION.pdf.

51. Zamora, Z. (2015). Las actitudes lingüísticas en Nicaragua/ Lo que pensamos los nicaragüenses sobre el español que hablamos. Managua: PAVSA. 


\section{Anexo 1: Abreviaturas con información sobre cada participante}

\begin{tabular}{|c|c|}
\hline MAJAY0112M & $\begin{array}{l}\text { MAJAY: Comunidad, Majayura/ 01: número del orden del entrevistado/1: grado de } \\
\text { instrucción: básica primaria/ 2: edad /: } 36 \text { años en adelante/ M: sexo, mujer. }\end{array}$ \\
\hline MAJAY0212M & $\begin{array}{l}\text { MAJAY: Comunidad, Majayura/ 02: número del orden del entrevistado/1: grado de } \\
\text { instrucción : básica primaria/ 2: edad: } 36 \text { años en adelante/ M: sexo, mujer. }\end{array}$ \\
\hline MAJAY0321M & $\begin{array}{l}\text { MAJAY: Comunidad, Majayura/ 03: número del orden del entrevistado/ 2: grado de } \\
\text { instrucción /: educación media/ 1: edad /: } 18-35 \text { años/ M: sexo, mujer. }\end{array}$ \\
\hline MAJAY0612H & $\begin{array}{l}\text { MAJAY: Comunidad, Majayura/ 06: número del orden del entrevistado/ 1: grado de } \\
\text { instrucción: básica primaria/ 2: edad: } 36 \text { años en adelante/ H: sexo, hombre. }\end{array}$ \\
\hline MAJAY0821M & $\begin{array}{l}\text { MAJAY: Comunidad, Majayura/ 08: número del orden del entrevistado/ 2: grado de } \\
\text { instrucción /: básica secundaria/ 1: edad: } 18-35 \text { años/ M: sexo, mujer. }\end{array}$ \\
\hline MAJAY0912H & $\begin{array}{l}\text { MAJAY: Comunidad, Majayura/ 09: número del orden del entrevistado/ 1: grado de } \\
\text { instrucción: básica primaria/ 2: edad /: } 36 \text { años en adelante/ H: sexo, hombre. }\end{array}$ \\
\hline MAJAY1011H & $\begin{array}{l}\text { MAJAY: Comunidad, Majayura/ 10: número del orden del entrevistado/1: grado de } \\
\text { instrucción : básica primaria/1: edad: } 18-35 \text { años/ } \mathrm{H} \text { : sexo, hombre. }\end{array}$ \\
\hline MAJAY1111H & $\begin{array}{l}\text { MAJAY: Comunidad, Majayura/11: número del orden del entrevistado/ 1: grado de } \\
\text { instrucción: básica primaria/ 1: edad : } 18-35 \text { años H: sexo, hombre. }\end{array}$ \\
\hline MAJAY1212H & $\begin{array}{l}\text { MAJAY: Comunidad, Majayura/12: número del orden del entrevistado/ 1: grado de } \\
\text { instrucción : básica primaria/ 2: edad: } 36 \text { años en adelante/ H: sexo, hombre. }\end{array}$ \\
\hline MAJAY1321H & $\begin{array}{l}\text { MAJAY: Comunidad, Majayura/13: número del orden del entrevistado/ 2: grado de } \\
\text { instrucción : básica secundaria/ 1: edad : } 18-35 \text { años/ } \mathrm{H} \text { : sexo, hombre. }\end{array}$ \\
\hline MAJAY1411H & $\begin{array}{l}\text { MAJAY: Comunidad, Majayura/14: número del orden del entrevistado/ 1: grado de } \\
\text { instrucción : básica secundaria/ 1: edad : } 18-35 \text { años/ H: sexo, hombre. }\end{array}$ \\
\hline
\end{tabular}

